\title{
El canto del pastor no espanta las ovejas: memoria y nostalgia en los versos improvisados de los emigrantes vascos ${ }^{1}$
}

\author{
The Song of the Shepherd Does not Scare the Sheep: \\ Memory and Nostalgia in the Improvised Verses \\ of Basque Emigrants
}

Pío Pérez

Universidad del País Vasco/Euskal Herriko Unibertsitatea pio.perez@ehu.eus

\section{RESUMEN}

El objetivo de este artículo es analizar la nostalgia que sufrieron los pastores vascos que emigraron a Estados Unidos mediante el análisis de su producción de versos improvisados. Estos versos improvisados abordaban sus añoranzas, sus deseos, opiniones e inquietudes de una manera enunciativa y emotiva, de una forma diferente de expresión que utilizan otros géneros narrativos, que tienden a proyectar esas emociones de manera más racionalizada. En el caso que nos ocupa, estos versos tienen una función testimonial, evocadora o emotiva que es perceptible de manera directa. Es decir, se erigen en textos evocadores complejos y multifacéticos que construyen la representación del proyecto migratorio.

Hoy en día sería unánime el acuerdo en considerar la literatura o el cine como productos culturales con una enorme relevancia social y que las representaciones que en esos productos culturales se reflejan son elaboraciones de unos discursos sociales e históricos. De la misma manera, estos versos vinculados con la emigración a América se constituyen como discursos sociales e históricos y como atalayas desde donde poder observar cómo se fue construyendo la realidad social de la emigración vasca.

Palabras clave: Nostalgia; Emigrantes; Pastores; Estados Unidos.

\section{SUMMARY}

The aim of this presentation is to reflect on the nostalgia suffered by Basque shepherds who emigrated to America, by analysing their production of improvised verses. These improvised verses addressed their homesickness, desires, opinions and concerns in a declarative and emotional way. While other narrative genres tend to represent these feelings in a more rationalized way, these verses tend to be evocative and emotional, with a testimonial function that is perceived more directly. In that respect, they become complex and multifaceted texts that influence the representation of identity and the migratory project.

\footnotetext{
${ }^{1}$ Quiero transmitir mi agradecimiento al Gobierno Vasco, ya que esta investigación ha sido posible gracias a la convocatoria para la movilidad de investigadores del programa Ikermugikortasuna (UPV/EHU MOVGV15/11).
} 
Nowadays, the consensus is that literature and cinema are cultural products with an enormous social relevance, and that they elaborate and represent social and historical discourses. Similarly, the verses of emigrants to America constitute social and historical discourses that let us reflect on the construction of the social reality of Basque emigration.

Key words: Nostalgia; Emigrants; Shepherds; United States of America.

\section{CANTAR. ¿QUÉ OTRA COSA PODÍAMOS HACER?}

Reno (Nevada), 23 de junio de 2015. Llevaba varios días paseando frente a la puerta del motel de la 4 th Street con esperanza de poder ver a Miguel Iturrino. Me acercaba a la puerta de la recepción y no se veía a nadie. Parecía cerrada, aunque un letrero de neón rojo anunciaba "open". Al tercer día opté por tocar un diminuto timbre colocado en la pared. Al rato pude escuchar una voz perdida que respondía desde el interior. Se asomó un señor, de alrededor de unos 70 años de edad, mayor, pelo cano, gafas y vestido con ropa de trabajo. Mister Iturrino?, le pregunte. Yes, yes. How are you?, fue su respuesta.

Alargué mi mano y me presenté: Arratsaldeon, Iturrino jauna, ni ere euskalduna naiz, zu ikustera etorri naiz ${ }^{2}$. Exhibió una alegre sonrisa y me devolvió el saludo. Después de presentarme y hablar sobre nuestras respectivas procedencias, le expliqué que había conocido su dirección en el Center for Basques Studies, que me encontraba aquellos días en Estados Unidos para investigar sobre la vida de los pastores vascos en el Norte de Nevada y más concretamente estaba interesado en el estudio de la nostalgia, que en euskara se denomina herrimina. Iturrino empezó a mover la cabeza de un lado para otro, intentaba colocarse bien las gafas, una y otra vez, de repente parecía nervioso. Casi un minuto de silencio más tarde me contestó que ya había hablado anteriormente con profesores del País Vasco. No quería contar a nadie más sus penas. Entonces fui yo el que me sentí incomodo, pensé que me había equivocado al presentarme en el motel y abordarle sin mucho preámbulo. Nos despedimos dándonos la mano y prometiéndonos una próxima visita.

Al día siguiente cuando comenté con un compañero del CBS mi visita a Iturrino, me aconsejó que acudiera cualquier tarde a la taberna Louis Basque Corner, ya que allí solían reunirse un grupo de antiguos pastores, entre ellos Iturrino, casi todos los jueves. El jueves por la tarde me acerqué a la taberna. El camarero, Frank, pronto supo que yo no era americano y me pregunto: where are you from? Le respondí que había llegado desde el País Vasco. Fue hacia una mesa donde estaban tres señores mayores y me invitó a sentarme con ellos. Me presenté y estreché sus manos. Los tres eran vascos y hablaban entre ellos en euskara, aunque alguno llevaba más de cuarenta años residiendo en los Estados Unidos, Los tres habían llegado a aquellas tierras a trabajar de pastores. Cualquier día de la semana acudían a aquel bar, pero los jueves no fallaban, cenaban en el restaurante y jugaban al mus. Hoy les había fallado el cuarto compañero, Iturrino.

\footnotetext{
${ }^{2}$ Buenas tardes, Sr. Iturrino, yo también soy vasco, he venido a verle. Todas las traducciones del texto son del autor. En los versos, se pone la traducción entre corchetes.
} 
Comenzamos hablando sobre nuestra procedencia vasca, dos eran vizcaínos, el otro era navarro y yo guipuzcoano. Cuando uno de ellos me preguntó cuál era el motivo de mi estancia allí respondí vagamente que había venido a la universidad, sin entrar en más detalles. Cuando les pregunte sobre su vida en Nevada contaron que habían venido a trabajar de pastores, en la década de 1960. Gogorra izango zen artzai lana, $e z$ ? $^{3}$ Hablamos sobre la dureza del trabajo, sus palabras reflejaban los duros años dedicados al pastoreo, las muchas horas de soledad, los peligros por el acecho de animales salvajes y la nostalgia por la lejanía de la tierra de origen. Cuando pregunté qué hacían cuando estaban solos con sus ovejas, con su perro y su caballo, uno de ellos, me respondió: kanta egin, zer egin ahal genuen, ba? Artzaiaren kantuak ez ditu ardiak uxatzen ${ }^{4}$. Yo pregunté: kantuan ibili? Zein kanta mota?., 5 Y la respuesta fue: denetarik, motel, denetarik, hango abestijak, bertsoak, gabon kantak be, denetarik ${ }^{6}$.

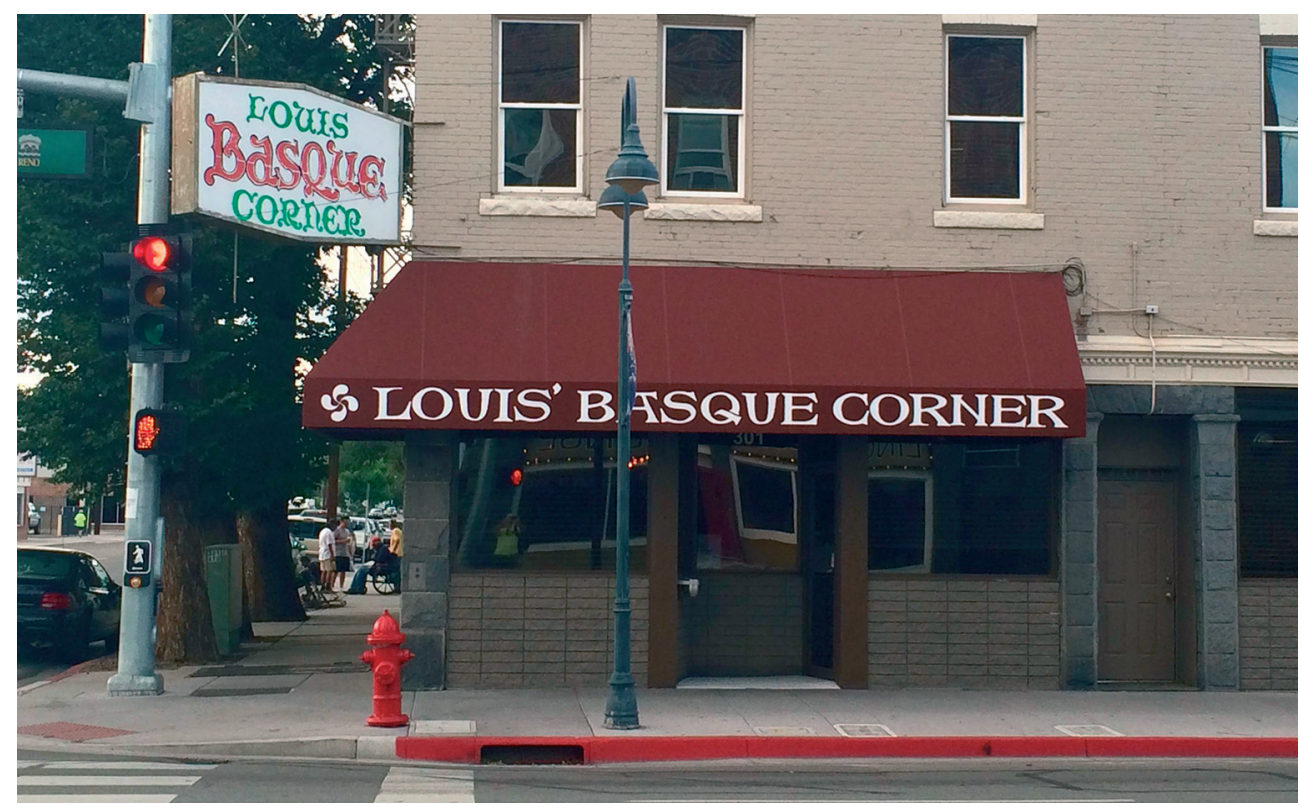

Imagen 1.-Louis Basque Corner, conocido local de Reno, lugar habitual de reunión de emigrantes vascos. Fotografía del autor.

El canto del pastor no espanta las ovejas, cantar espanta los demonios. Cuando me retiré y me despedí de mis compañeros de partida, recordé una investigación anterior que realicé sobre una familia de improvisadores de versos, los Zapirain (Pérez 2014). Joxe Zapirain, el padre, recurría al canto y a la improvisación de versos de manera terapéutica y taumatúrgica, con ellos espantaba sus demonios. De la misma

\footnotetext{
${ }^{3}$ Un duro trabajo, no?

${ }^{4}$ Cantar. ¿Qué otra cosa podía hacer? El canto del pastor no espanta las ovejas.

5 Cantar? Que cantabais.

${ }^{6}$ De todo, canciones vascas, bertsoak y hasta villancicos también.
} 
manera, aquellos emigrantes vascos que había tenido enfrente habían recurrido al canto y a la improvisación de versos para plasmar y combatir sus añoranzas.

Por medio de este artículo he querido reflejar los lamentos de estos pastores ante la nostalgia, la soledad o las difíciles condiciones de trabajo en los montes y páramos desérticos del Oeste americano. Para acercarme a esas experiencias he recopilado algunos de los versos improvisados por estos pastores. A pesar de la fugacidad intrínseca de este tipo de composiciones existen un gran número de ellas publicadas en libros, revistas o recogidas en el archivo de la Basque Library de la Universidad de Reno. La intención de estas líneas es ofrecer un enfoque de la emigración y de la vida de los pastores vascos en América de una manera evocativa y emotiva de manera distinta de la que pudieran haber expresado estos mismos pastores al utilizar otros géneros narrativos que tienden a proyectar esas emociones de manera más racionalizada. A pesar de ser consciente de que estas composiciones deberían ser leídas o escuchadas en su totalidad, por razones de espacio en este artículo aparecerá una selección de las estrofas que considero más adecuadas al tema a tratar y no las improvisaciones al completo.

\section{LA EMIGRACIÓN VASCA HACIA AMÉRICA: EL PASTOREO}

En la obra en la que analizaba el fenómeno migratorio, el escritor Pierre Lhande (1971: 9) señaló que eran tres las condiciones indispensables para poder considerarse vasco: la primera era tener un apellido bien sonoro, la segunda era el conocer la lengua vasca, y la tercera era tener un tío en América. Con la tercera de las condiciones Lhande resaltaba la importancia que el fenómeno migratorio, sobre todo el destinado a tierras americanas, había tenido en la configuración de la población y del imaginario de los vascos y vascas. No es aventurado considerar que junto con los conflictos armados sufridos y con los procesos de industrialización conocidos, la emigración se ha constituido como el fenómeno social que más ha afectado a la vida cotidiana del País Vasco Por ejemplo, la emigración ha tenido una importancia capital en la estructura demográfica de la población y es bien difícil encontrar aspectos de la historia y de la sociedad vasca que no hayan sido, de alguna manera o de otra, afectados por la cuestión migratoria (Álvarez Gila 2004: 73).

El anteriormente citado Lhande presentó la emigración como un fenómeno natural y su explicación se acercaba más al supuesto atavismo de la población vasca que a causas socio-económicas. Pero, para llegar a entender los motivos que puedan explicar la masiva emigración a tierras americanas debemos de mirar ineludiblemente a la economía. De alguna manera, es constatable a nivel general que las dificultades económicas pueden explicar la salida de numerosas personas de sus lugares de origen en la búsqueda de un mayor bienestar o de un futuro próspero. En el ámbito geográfico vasco el fenómeno podía relacionarse con la crisis producida por el paso de una sociedad basada en una economía agrícola a una sociedad industrial; también con la dificultad de gestionar la presión demográfica que se estaba produciendo desde mediados del siglo XIX; sin olvidar las guerras carlistas, la I Guerra Mundial o el posterior éxodo político relacionado con la guerra civil española. A esta diversidad de factores debe añadirse la institución del mayorazgo: el sistema de repartición de la herencia 
en el ámbito rural. El mayorazgo era la estrategia utilizada para preservar el patrimonio familiar. Mediante esta institución, las familias de propietarios elaboraban complejas estrategias para transmitir los bienes a un solo heredero. Esta forma de transmisión hereditaria empujaba a los hijos e hijas que no estaban en condiciones de heredar a pensar en elaborar su propio proyecto migratorio (Douglass y Bilbao 1986).

Lo que Douglass y Bilbao (1986) denominaron la época moderna de la emigración hacia el otro lado del Atlántico tuvo su inicio en los primeros años de la década de los años 30 del siglo XIX, que es cuando se comienza a constatar un importante éxodo rural en el agro del País Vasco (Arrizabalaga 2010: 113). Las recién creadas repúblicas del cono sudamericano necesitaban gran número de personas jóvenes y fuertes (Medina 1997: 13) para poder desarrollar con eficacia su nueva estructura estatal y colonizar las tierras en defensa de su construcción nacional. En el año 1824, Argentina creo la Comisión de Emigración que tenía el objetivo prioritario de habilitar medidas legislativas y administrativas que atrajesen mano de obra europea (Azcona 1998: 28). Años después, autoridades uruguayas comenzaron una política aperturista hacia los emigrantes que hizo que entre los años 1835 y 1842 entrasen en el país 33.000 europeos, la mayoría de ellos italianos y vascos (Azcona 1998: 28). A principios de la década de 1850, en los municipios vascos se fueron generalizando la presencia de los agentes de emigración, popularmente llamados enganchadores. Estos agentes animaban a los jóvenes a partir hacia América y les proporcionaban algún préstamo que les permitiese adquirir el billete, al tiempo que les garantizaban un empleo estable al otro lado del océano, que en numerosas ocasiones era para trabajar como pastor en la Pampa argentina o chilena (Santiso 1998: 22).

Entre 1848 y 1855, durante el Californian Gold Rush, las noticias del descubrimiento de oro animaron a muchos europeos que habían partido hacia el cono suramericano a trasladarse hacia las tierras californianas con la esperanza de encontrar allí una rápida fortuna (Gachiteguy 1955: 8). Los campamentos mineros y los núcleos de población que surgieron tras la fiebre del oro necesitaban provisiones alimentarias y éstas fueron satisfechas mediante el consumo de la carne de oveja. Durante las dos primeras décadas esta industria ganadera se expandió a un ritmo exponencial (Douglass y Bilbao 1986: 279). Los emigrantes vascos que habían arribado al Oeste Americano se dedicaron al trabajo que les había llevado primeramente al sur del continente: al pastoreo (Garikano 2009: 15). Estos pastores que estaban comenzado a asentarse en los montes y valles californianos debían la experiencia necesaria en el manejo de rebaños ovinos a gran escala a su trabajo en la Pampa Argentina, allí aprendieron las técnicas del pastoreo en pastos abiertos en condiciones que se asemejaban a las que se iban a encontrar en el sur de California (Douglass y Bilbao 1986: 281).

Dirigiéndose primero hacia Argentina, Uruguay o Chile y luego California, los jóvenes vascos - la mayoría eran varones jóvenes - fueron abandonando las casas solariegas y los pequeños pueblos de las montañas para dedicarse al pastoreo a gran escala. Esta emigración masiva fue notoria en numerosos valles del Pirineo, aunque fue más acusada en los pueblos de la zona bajo navarra (Arrizabalaga 2010:14). El resto del País Vasco también conoció una fuerte emigración, aunque a veces debía realizarse de manera clandestina, como cuando en Guipúzcoa se decretó la prohibición de emigrar entre 1870 y 1880 (Santiso 1998: 44). Según se recoge en un censo de la población de 1900 en el Oeste americano, un gran número de estos pastores 
emigrantes vascos partieron desde los puertos de Bayona o desde el vecino puerto de Burdeos (Bilbao y Eguiluz 1984). Muchos de aquellos pasajeros eran guipuzcoanos que embarcaron desde los puertos citados desobedeciendo las leyes antiinmigración (Pildain 1984: 80).

Finalizada la década de 1870, la sobreexplotación de la ganadería ovina comenzó a mostrarse de manera muy notoria en California, entonces los ganaderos y pastores vascos comenzaron a dirigir sus rebaños de ovejas a las vecinos pastos públicos de los estados de Nevada, Oregón o Idaho (Douglass y Bilbao 1986: 290). Estos ovejeros, al hacerse propietarios, contrataban a parientes o a vecinos de sus mismos lugares de origen para ayudarse en su trabajo, con lo que la llamada a la emigración fue constante y sin la necesidad de enganchadores (ibid: 290). Así ocurría que los nuevos pastores que emigraban a los Estados Unidos eran jóvenes que empezaban a trabajar en el pastoreo bajo las órdenes de un ganadero también de origen vasco. Estos pastores jóvenes en muchas ocasiones cobraban su salario en especie lo que les permitía en un plazo de cuatro o cinco años la propiedad de su propio rebaño. Es decir, cuando este rebaño tenía el suficiente número de cabezas conseguido como salario para subsistir en el negocio, el pastor asalariado se convertía en ganadero propietario y volvía a contratar a parientes o vecinos de su pueblo para atender a sus ovejas (ibid. 1986: 262). La inversión necesaria para mantenerse en el negocio no era cuantiosa, además de las ovejas obtenidas como salario, un par de perros, un caballo y algún arma de fuego era lo estrictamente necesario para el pastoreo trashumante (Fernández de Larrinoa 1992: 43). Durante más de un siglo la práctica totalidad de los pastores que trashumaban con sus rebaños por el Oeste norteamericano eran vascos (Pipkin 1997: 26), con lo que fue extendiéndose en los Estados Unidos la identificación de lo vasco como ligado por ley natural al pastoreo, y en el País Vasco la idea del indiano que había salido de su pueblo para ser pastor y que regresaba después de unos años de duro trabajo con los bolsillos llenos de dinero. La concepción del emigrante que volvía al hogar con una buena fortuna se recoge en el imaginario vasco y se concreta en este popular verso que resume de manera clara las ilusiones y oportunidades que se esperaban tras el periplo americano:

\author{
Ameriketara joan nintzan \\ zentimorik gabe \\ handik etorri nintzan, maitea, \\ bost milloiren jabe. \\ Txin, txin, txin, txin, \\ diruaren hotsa, \\ haretxek ematen dit, maitea, \\ bihotzean poza.
}

[Emigré hacia América sin un céntimo y desde allí volví, amor mío, con 5 millones. Chin, chin, chin chin, el retintín del dinero, amor mío, es lo que me alegra el corazón.]

En el año 1921, el Congreso de Estados Unidos consideró que debía de restringir la presencia de trabajadores foráneos dentro de sus fronteras y prohibir su entrada, por ello aprobó una ley que regulaba drásticamente la emigración europea. Entre estas medidas legislativas antiinmigración se decretaron unos cupos que restringía severamente la entrada de trabajadores europeos, lo que afectó seriamente al acceso de 
emigrantes vascos. A estas medidas hubo que añadir la promulgación de otras leyes que afectaban a la regulación sobre las tierras de domino público que fueron aprobadas a finales de esa misma década y concretamente la ley contra el pastoreo, llamada Taylor Grazing Act que pretendió regular el pastoreo excesivo en numerosas zonas del Oeste Americano (Saitua 2015: 2120). Las consecuencias de las dos medidas legislativas citadas antes y las constantes fluctuaciones del mercado de la carne ovina pusieron en grave crisis la continuidad del pastoreo trashumante (Bieter y Bieter 2005: 93) con lo que el próspero negocio ganadero ovino entró en una grave crisis de subsistencia y prácticamente desapareció en los años de la Gran Depresión (Mallea-Olaetxe 2009: 31).

Dos décadas después, en 1940, el mismo Congreso americano aprobó las denominadas leyes sobre pastores de ovejas (Shepherder Laws) que legalizaban de hecho las situaciones de algunos pastores vascos que están trabajando en los estados de California, Nevada, Oregón e Idaho de forma irregular. Esta legislación permitió que 383 pastores vas-

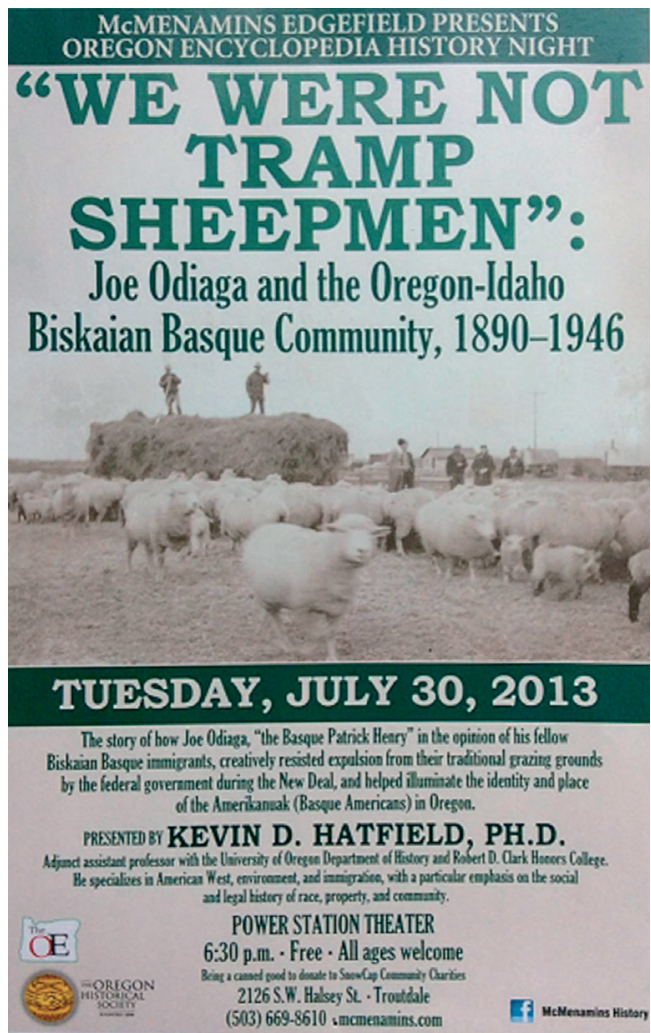

IMAGEN 2.-Cartel anunciador de una conferencia sobre el pastoreo vasco en USA.

Fotografía del autor. cos obtuvieran la residencia permanente y su derecho a trabajar en los Estados Unidos (Orduña 2012: 413). Estos pastores fueron conocidos como los "Tram Shepherders", pastores vagabundos que deambulaban libremente por los pastos públicos americanos buscando las mejores tierras donde dar de comer a sus rebaños (Saitua 2015: 2126). En 1942, se constituyó la Asociación de Propietarios de Pastos para Ovejas (Nevada Range Sheep Ownes Asociation) que ofrecía contratos a pastores procedentes del País Vasco para trabajar en tierras del estado de Nevada. A instancias de esta asociación se autorizó la entrada de una cuota de 500 Spanish Sepherders. Años después, en 1966, los ganaderos ovejeros del Oeste se reunieron para fundar la Western Range Association, con el mismo objetivo de reclutar buenos pastores vascos que cuidasen de sus rebaños. La citada asociación estaba dirigida por un ganadero de origen vasco, José Mendiburu, natural del Valle de Baztán (Navarra) que emigró a tierras americanas en su juventud (Sorozabal Esnaola 1992: 43). En 1970, se alcanzó el número más alto de pastores europeos contratados, alrededor de 1500 de los que el 90 por ciento procedían de municipios vascos (Orduña 2012: 414). Hoy en día, en los ranchos norteamericanos no trabajan pastores vascos, la procedencia de estos nuevos pastores hay que situarla en el altiplano peruano. La 
economía y las condiciones de vida en las zonas rurales europeas ha mejorado lo suficiente para que la llamada americana no surta efecto entre los jóvenes y el supuesto atavismo vasco se canaliza de otras maneras.

El pastoreo fue la principal profesión de los vascos emigrantes, comenzaron en el oficio en la Pampa argentina y después se trasladaron al oeste americano. En estos dos países el buen nombre acompañaba a los vascos emigrantes. En estos versos se ensalza el buen hacer y la profesionalidad de los pastores vascos, que eran unos trabajadores responsables y conocedores de su oficio, idea que fue extendiéndose por tierras americanas.

\author{
Nik gaur nere besuan \\ zorionikan beroenak \\ eman zenduten pausuan; \\ or zabiltzate orain ardi zai \\ mendian edo basuan, \\ euskaldun jatorra ezagun baita \\ Ameriketa osuan. (Zavala 1984: 133)
}

[Quiero ofrecer mi agradecimiento a todos los que habéis dado el salto y os encontráis ahora trabajando de pastores en el monte o en el bosque. El vasco virtuoso es conocido en toda América.]

La identificación entre vascos y pastoreo era total. Hoy en día, esta identificación se mantiene viva en numerosos lugares de Estados Unidos, hasta la creencia de que todos los vascos han sido en algún momento de su vida pastores o conocen de manera innata el oficio de pastor. Así le ocurrió a un estudiante de doctorado del Center of Basque Studies que fue a pedir trabajo en un rancho ovejero de Nevada para conseguir algo de dinero en sus vacaciones. Al preguntarle por su procedencia, el contestó: from the Basque Country. Estas cuatro palabras que hablaban de su origen sirvieron para ser contratado sin necesidad de demostrar que conocía el oficio, ya que el ganadero supuso que si era vasco debía conocer perfectamente el trabajo con las ovejas.

Como hemos dicho anteriormente, los emigrantes que abandonaron su hogar y marcharon a América recuerdan con nostalgia y con melancolía las cosas y las vivencias que dejaron aquí, pero al mismo tiempo eran conscientes que el viaje les podía servir para aprovechar las oportunidades que les ofrecían las tierras americanas. Aunque el discurso en torno a la emigración parece resaltar las emociones de la nostalgia y del desarraigo, muchas veces la tierra de destino se percibe como el espacio físico y social necesario que permite comenzar una nueva vida. Este agradecimiento a la tierra de acogida se simboliza en los siguientes versos en la figura de un árbol característico de la Pampa argentina, el ombú. Así cantaba Otaño al árbol ombú que tenía al lado de su chabola (1904: 48) en los inicios del siglo XX, mientras trabajaba en la Pampa argentina cuidando ovejas. Este árbol, además de proporcionarle sombra y compañía, le acercaba al recuerdo del frondoso nogal que había en la entrada de su casa en su Zizurkil natal.

Txabol ondoko ombú laztana,

Maitatzen zaitut gogotik

Eta biyotza erdibitzen zait 


\author{
Joatian zure ondotik, \\ Nere burura ekartzen dezun \\ Oroimen gozuagatik. \\ Zure itxura nai det ikusi \\ Ez dizut eskatzen frutik \\ Ni emen bizi naizen artian \\ Arren! egon zaite zutik!
}

[Querido ombú que estas al lado de mi cabaña, te amo de verdad por los dulces recuerdos que me evocas y es posible que se me rompa el corazón cuando tenga que abandonarte. Quiero ver tu presencia, no pido que me ofrezcas tu fruto, sólo que te mantengas en pie mientras viva aquí.]

\author{
Nere lagunik maitatuena \\ Ombú laztana, zu zera, \\ Argatik nator zure kolkora, \\ Ni malkuak isurtzera, \\ Iduriturik naramazula \\ Atariko intxaurpera... \\ Beti izango zaitut, goguan, \\ Bañan joan nai det ostera, \\ Euskal-lurreko arbolpe artan \\ Nere ezurrak uztera.
}

[Ombú, tú eres mi mejor amigo, por eso acudo a tu regazo a derramar mis lágrimas, ya que trasladas a mi memoria el nogal que existía en la entrada de mi casa natal. Siempre te llevaré conmigo, pero quiero que mis huesos reposen bajo el árbol de la tierra vasca.]

\title{
3. LA EMIGRACIÓN HACIA AMÉRICA COMO TEMA DE LOS VERSOS IMPROVISADOS
}

La emigración a tierras americanas ha ido dejando numerosos rastros en el imaginario y ha pasado a considerarse un fenómeno de carácter colectivo, a pesar de que la emigración se presenta como una elección de tipo personal. Estas huellas en torno a la emigración a América pueden rastrearse desde el análisis de la producción de los versos improvisados en euskara (Zavala 1983: 12), ya que los improvisadores o bertsolariak ${ }^{7}$ han sido una referencia en la comunidad vascoparlante y han tenido una gran importancia en su papel de comunicadores sociales. Se puede afirmar que los versos improvisados se han constituido como la forma de comunicación social más utilizada entre la comunidad vascoparlante a lo largo de la historia (Garzia 2008). Una comunicación social de tipo subalterno, al estilo gramsciano, frente a la minoría alfabetizada que se comunicaba en español o en francés en sus escritos (Eizagirre 2007: 11). Uno de los motivos que puede explicar la importancia de la versificación improvisada en la comunicación dentro de los vascoparlantes está relacionado con los importantes índices de analfabetismo que se registraban y la nula alfabetización en la propia lengua vasca, lo que posibilitó que la improvisación versificada pudiera ser considerada como la voz pública del pueblo llano (Dávila 1995: 261).

A menudo, los vascoparlantes han vehiculizado y transmitido mediante los versos improvisados experiencias y emociones que por otros medios no podían expresar. Así

\footnotetext{
${ }^{7}$ Así se denominan en euskara a los improvisadores de versos.
} 
lo hicieron los pastores emigrados a tierras americanas que aliviaban su nostalgia por la lejanía de su tierra natal cantando bertsoak ${ }^{8}$ en la soledad de los desiertos norteamericanos (Garikano 2009). Se podría indicar que el análisis de la producción de versos improvisados puede ser un observatorio privilegiado para analizar las vivencias personales y el contexto socio-histórico de la emigración de los vascos a América.

Una de las primeras relaciones entre emigración e improvisación de versos puede situarse en los primeros juegos florales que Antoine de Abbadie convocó en el municipio labortano de Urruña (Urrugne) en el año 1853, en el que el tema propuesto para el concurso de poesía fue la emigración a América. El título elegido para el certamen fue: Montevideora dihoan euskal gaztearen bihotz-minak9 (Urkizu 1977: 15). Entre los siete participantes se encontraba el entonces aclamado poeta Pierre Topet Etxahun (1786-1862) que presentó a concurso los versos denominados Montebideorat juailiak ${ }^{10}$. En aquella edición el vencedor fue Bernard Celhabe que escribió el tema Entzunik espantutan Indien berria $^{11}$. He recogido en estas líneas tres estrofas de la composición ganadora en las que aparecen de manera clara las emociones ligadas a la nostalgia por encontrarse lejos del hogar y al dolor producido por el abandono del lugar de origen:
Diruaren goseak etxetik narama,
Utzi behar dut aita, utzi behar ama, Segurantzarik gabe niboiz biburtzeko, Iragan atseginak berriz kobratzeko.

[La codicia del dinero me hace partir, debo abandonar a mi padre y a mi madre, y convertirme en un Don Nadie, desprotegido, (mi consuelo) llega de recordar agradables aconteceres del pasado.]
Adios, Eskual-Herri hanbat onhetsia,
Hire zerua zaitak ezin ahantzia,
Uzten darozkitziat maite ditudanak,
Ethor bahi, aita-amak, haurreko lagunak.

[Adiós tierra vasca tantas veces admirada, no puedo olvidar tus cielos y amo todo aquello me ofreces, venid hacia mi recuerdo, padres y amigos de la infancia.]
Noizbait ahanzten badut ene ama ona,
Beldur ez nadin ethor, nigarrez dagona,
Ahanzten badut aita, ahanzten berria,
Nihoiz ez bekit mugi aboan mihia. (Urkizu 1977).

[Si alguna vez olvido a mi buena madre, a ella, que me protege frente al miedo y que ahora llora, si alguna vez olvido a mi padre, si llego a olvidar mi pueblo, ojalá me quede mudo, con la lengua inmovilizada.]

En aquel contexto histórico la elección de aquel tema en el norte del País Vasco no fue una casualidad ni una ocurrencia de los organizadores (Davant 1997: 70), ya que la emigración estaba en el pensamiento de toda la población y era una de las preocupaciones más acuciantes para la sociedad de la época (Álvarez Gila 1998; Álvarez Gila y

\footnotetext{
${ }^{8}$ Versos improvisados.

9 Los sufrimientos del joven vasco que marcha a Montevideo.

${ }^{10}$ Los que partieron a Montevideo.

11 Escucho con asombro noticias de las Indias.
} 
Tapiz Fernández 1996). La opinión pública de la época consideraba que la llamada americana arrebataba a los pequeños municipios del norte del País una fuerza de trabajo joven e importante, lo que ponía en serio peligro la supervivencia de numerosos pueblos y caseríos. Eran numerosas las ocasiones en las que a estos emigrantes se les acusaba de egoístas, de intentar ganar dinero fácil, de falta de compromiso con la familia que les vio nacer, o de carencia de patriotismo (Arrizabalaga 2010: 117). La inquietud social por la emigración llevó a la proliferación de documentos a lo largo del siglo XIX en los que se ofrecía una interpretación pesimista del fenómeno, lo que motivó a que las autoridades del momento promovieran políticas migratorias bastante restrictivas en algunos territorios (Fernández 2014: 252). En este rechazo a la emigración masiva la iglesia vasca jugó un papel importante. Las cartas pastorales de los obispos de Pamplona, Bayona y Vitoria en los años 1852, 1855, y 1867 contra la emigración son un claro ejemplo del sentir contrario de la iglesia vasca contra el éxodo a América (Álvarez Gila 2004). En la literatura vasca de finales del siglo XIX también aparece el amerikanua o indianua, el emigrante vasco que regresaba enriquecido de su periplo americano. Su representación era mayoritariamente negativa y estaba claramente condicionada por la ilusión del eterno retorno a la tierra madre. América era el lugar donde los vascos emigrantes corrían el riesgo de perder la fe, era un lugar de peligro para el alma de los vascos y donde ante todo reinaba el vicio y la perversión (Olaziregi 2012: 147).

Muchos de aquellos pastores que marcharon a tierras americanas retornaron más tarde a su tierra de origen, pero otros muchos no y acabaron integrándose en la vida y costumbres americanas. Muchos se asentaron en ciudades del Oeste americano, formaron nuevas familias no tenían entre sus prioridades más inmediatas el retorno. En este verso, improvisado en un certamen de bertsolaris americanos, Jesús Goñi, antiguo pastor que partió hacia Estados Unidos en la década de 1960 desde su pueblo de Oronoz (Navarra) reivindica el derecho de disfrutar de las comodidades y de los avances que ofrece la sociedad americana. Después de los años duros, solitarios y difíciles en los que estuvieron trabajando como pastores, ahora les corresponde disfrutar de lo ganado. Jesús Goñi, es hoy uno de los improvisadores más conocidos entre la comunidad vasco-americana y no hay festival en la Diáspora que no cuente con su actuación:

Agur orain mendiari,
Agur ere artaldia,
Urte askoren buruan
Komeni zait abaztutzia;
Arrantxo bazterrian daude
Zakurra eta zaldia
Karreteran espero ditut
Neskatxa eta kotxia. (Mallea-Olaetxe 2005: 242)

[En estos momentos debo de despedirme de las praderas y del rebaño, después de tantos años os debo olvidar, allí en un rincón del rancho dejé abandonados al perro y al caballo, ahora en la carretera me espera un coche y una mujer.]

Retomando la mencionada relación entre emigración y versificación improvisada, es necesario citar la cantidad importante de improvisadores y bertsozaleak ${ }^{12}$ que par-

${ }^{12}$ Se denomina bertsozaleak a las personas aficionadas a la improvisación poética, ya se dediquen a la creación de estas composiciones o no. 
tieron hacia el continente americano, prácticamente todos acudieron a trabajar en aquellas tierras como pastores. Junto a los populares y entonces consagrados improvisadores del siglo XIX, como Pedro María Otaño y José María Iparragirre, se pueden enumerar, entre otros, a José Mendiague, Pierra Merkapide, Juan Pedro Etxamendy, Jesús Goni, Jesús Arriada, Johnny Kurutchet, Juan Cruz Arrosagary, Paulo y Josetxo Yanzi, Manex Etchamendy o Mixel Aire. Algunos de estos improvisadores vieron sus creaciones publicadas en revistas editadas en euskara como Bertsolari, Herria, o Zeruko Argia o en otras como Príncipe de Viana. También hay que mencionar algunos de los libros publicados por estos versificadores como es el caso de Otaño, Arrosagary, Etxamendy, Yanzi o Mendiague, también son de destacar las publicaciones en las que se recogen estos versos promovidos por distintos editores entre los que se pueden destacar las obras de investigación de Piarres Lafitte (1972), Piarres Xarriton (1992), Antonio Zavala (1968, 1983, 1984) o Joxe Mallea-Olaetxea (2003, 2005).

En la actualidad, en las fiestas organizadas por las comunidades de vasco-americanos no puede faltar el tradicional espacio dedicado a estos improvisadores. La actuación de los bertsolariak es uno de los actos importantes de cualquier celebración de la comunidad vasca en la diáspora, (Oiarzabal 2009: 264) ya sean estos bertsolariak contratados exprofeso desde el País Vasco o ciudadanos vasco-americanos que son

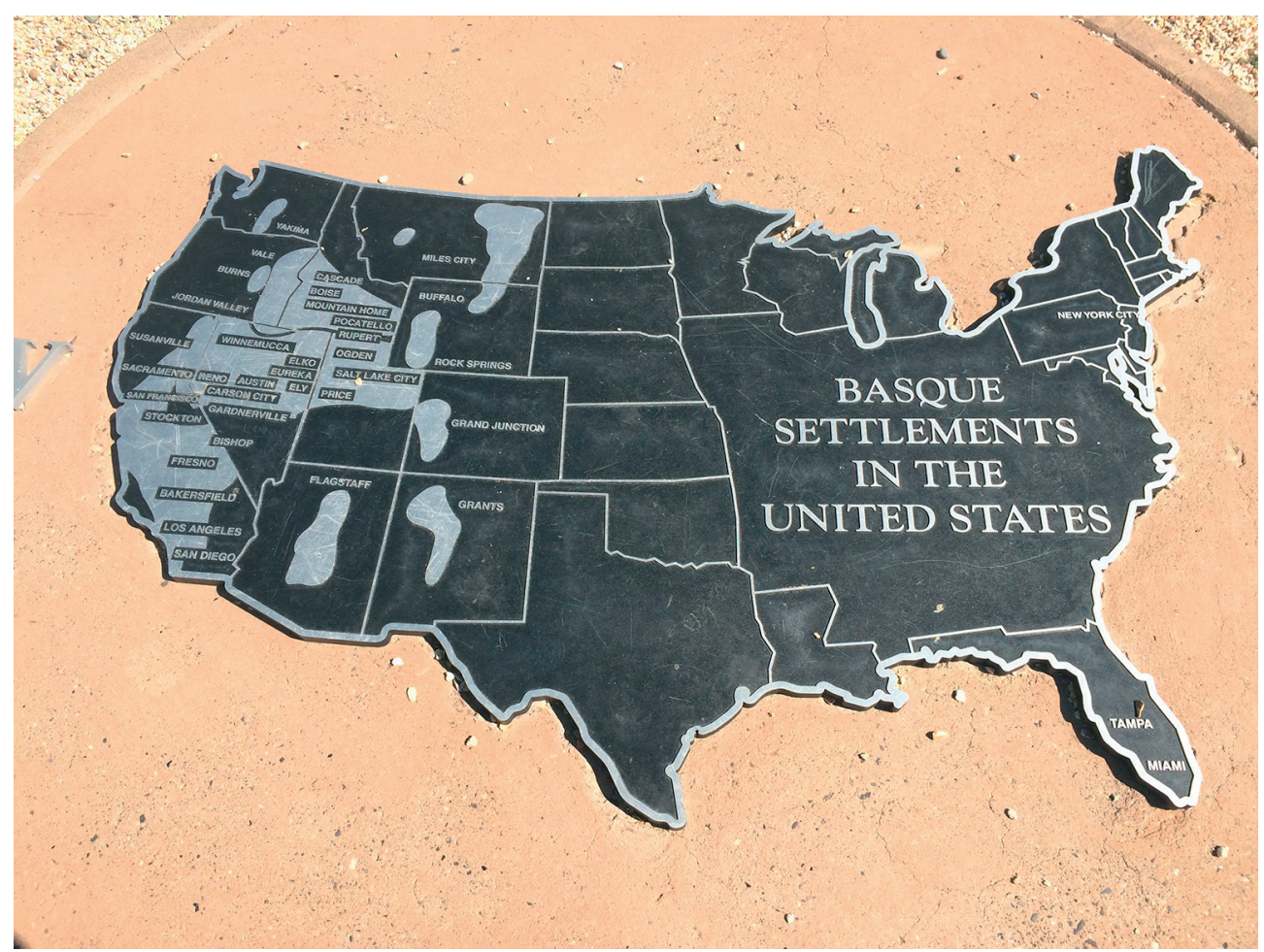

IMAGEN 3.-Lápida que recoge la expansión de la emigración vasca en tierras norteamericanas. Foto del autor. 
hábiles en la improvisación. En el festival de la comunidad vasco-americana que celebró en el verano de 2015 en Boise (Idaho) estaba anunciada la actuación de dos bertsolariak que viajaban desde el País Vasco: Nerea Ibarzabal y Xabier Paya, que acompañaban a otros improvisadores vascos residentes en USA. En este sentido, hay que mencionar como anécdota que en el año 1988 se celebró en el estado Nevada (Gardnerville) el primer Campeonato de Estados Unidos de bertsolariak. Las improvisaciones de versos se cantaron ante más de 1000 personas procedentes de todo los Estados Unidos y participaron los navarros Goñi, Arriada, el californiano Kurutchet y el vizcaíno Txurruka. El vencedor resultó ser el oronoztarra Jesus Goñi (Aristorena 1992: 55).

\section{LA VERSIFICACIÓN IMPROVISADA, UNA COSTUMBRE ARRAIGADA ENTRE LOS PASTORES EMIGRANTES}

Es abundante la producción de versos recogidos entre los pastores vascos afincados en tierras americanas, lo que puede indicar que la improvisación poética era una práctica habitual entre ellos. Se puede pensar que a menudo recurrían al canto mientras trabajaban en el monte o en el desierto cuidando sus rebaños, en esos momentos de soledad el canto y la creación de los versos les acompañaba. El verso improvisado se canta, y generalmente se canta en voz alta. Así acostumbraban a hacerlo los pastores vascos en tierras americanas, su propia voz les ayudaba a combatir la soledad, al mismo tiempo que la capacidad taumatúrgica del canto les aliviaba sus angustias diarias. De alguna manera, la improvisación de versos, como el canto o como las maldiciones son distintas maneras de aliviar la tormenta interior surgida por sucesos o situaciones de origen traumáticas. Es decir, aquellos pastores que iban improvisando sus versos en viva voz lo hacían pensando en la capacidad que aquellas improvisaciones podían tener para influir en el mundo que les rodeaba. Los versos, al igual que ocurre con las maldiciones, deben de ser recreados en voz alta. La persona que recurre a maldición no lo hace en voz baja, hay que maldecir con la voz elevada, ya que es una manera de protegerse (Valcárcel 2010: 48). La voz del maldiciente llegará, se extenderá, alguien conocerá la maldición y tomará venganza o justicia, o recordará esas palabras (ibid:: 48). Así funcionaba la improvisación versificadora en los montes y desiertos norteamericanos, había que cantar las penas en voz alta, que se extendiera el lamento de los pastores, que se conociera su situación, que se supiera de su trabajo o de los peligros que diariamente les acechaban, que nadie pudiera pensar que Norteamérica era sinónimo de riqueza y buena vida.

El poeta Koldo Jauregi recopiló unos versos de un improvisador que firmaba sus composiciones como Nevadako Artzaina (El pastor de Nevada) y los publicó en la revista de literatura vasca Egan. Este versificador que firma como "Pastor de Nevada" habla del canto como una labor habitual entre los pastores, así lo apunta en esta estrofa publicada en la citada revista:

Lagunak banituen jiteko bidian, Orai barreatuak eremu haundian

Heien berririk ez dizu yuan den aspaldian. 
Berantetsia nago bemen, errabian,

Kantuz ukhanen ditut bek ere agian! (Jauregi 1950:13)

[Tenía amigos que vinieron de viaje, ahora estarán desperdigados en estos parajes inmensos. No tengo noticias suyas desde hace tiempo y estoy impaciente aquí, rabioso por no saber nada de ellos, es posible que mis amigos también estén cantando.]

Otro pastor improvisador del norte del País Vasco, Charles Ugalde, también refleja la costumbre que tenían muchos emigrantes de improvisar versos mientras cuidaban las ovejas. El canto de versos era una tarea a la que se entregaban durante muchos momentos del día. En los encuentros de improvisadores una de las modalidades principales consiste en el duelo entre dos o más versificadores. Es decir, un bertsolari acomete su versificación en controversia con otro, en el que uno desarrolla un discurso y su contrincante le responde matizándole o con argumentos contrarios (Garzia et al. 2001: 104). Ugalde en esta estrofa de su verso Nik eta nirea astoak ${ }^{13}$ hace referencia a esta modalidad de improvisar en controversia con otro y cómo en su soledad este pastor tenía que recurrir a su burro como contrincante.

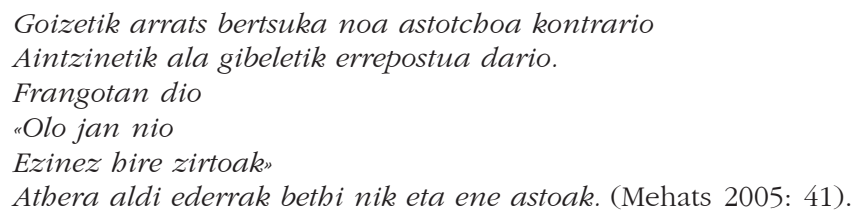

[Desde la mañana hasta la noche paso el día cantando, teniendo como contrincante al burro, por delante o por detrás le surgen las ocurrencias. A menudo repite: no puedo con tu palabrería, avena comería. Los dos tenemos buenas salidas.]

Esta reiterada costumbre de cantar e improvisar versos también es recogida en estas estrofas de Manex Etchamendy. De esta manera lo expresaba en la primera estrofa de una composición que dedicó a aquellos que como él se dedicaban al trabajo del pastoreo en los montes y desiertos de Nevada:

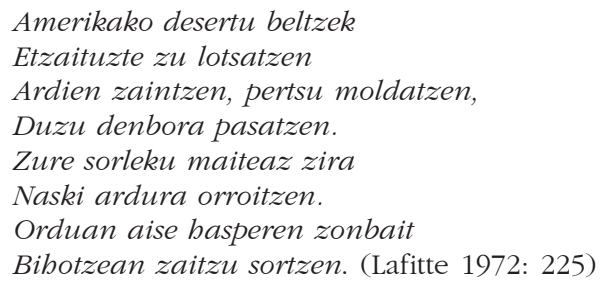

[No te asustan los desiertos negros americanos, en ellos pasas tu tiempo cuidando ovejas y construyendo versos. En esos momentos recuerdas con amor tu lugar de origen mientras tu corazón suspira.]

Hay que mencionar que algunos de los pastores que después de su periplo americano volvieron a sus lugares de origen, narraron sus experiencias en Nevada o California y las plasmaron por medio de los versos improvisados. Era una manera de ir contan-

\footnotetext{
${ }^{13}$ Yo y mis burros.
} 
do su experiencia y emociones vividas, al tiempo que anunciaban a los jóvenes aspirantes a pastor de lo que se podían encontrar allí. Es el caso de Paulo Yanzi, un pastor natural de Lesaka (Navarra), por medio de la versificación improvisada se dirige en carta a su sobrino, recién llegado al Oeste americano, con la finalidad de explicarle la vida y la dureza del trabajo que va a encontrar en aquellos montes y desiertos americanos. Yanzi, conocedor del oficio pastoril y de la vida en aquellas tierras, advierte a su sobrino de los numerosos peligros que un joven vasco puede encontrar en las calles de las ciudades norteamericanas, para acabar recordándole que tenga claro que ha marchado de su hogar ha sido con el objetivo de trabajar duro, de ganar y ahorrar dinero:

\author{
Josetxo, ditzu osaba zarrak \\ Egi batzuek esango \\ Banan itz okin pena aundirik \\ Ez dizut emango, \\ Orai modua danian dantzatu \\ Asko jota eta fandango \\ Nola bakarrik ardi zaitzera mendira zeran joango \\ An dezu zure Margaritan \\ Laguntzarikan izango. (Zavala 1968: 127)
}

[Josetxo, tu viejo tío quiere decirte unas palabras, sin ánimo de apenarte, disfruta como sabes del baile, de la jota y del fandango, ya que vas a estar muy solo en el monte cuidando las ovejas, allí no tendrás a Margarita para ayudarte.]

Su sobrino, Josetxo Yanzi, le respondió escribiéndole otros versos improvisados. En su composición quiere hacer saber a su tío que ha recibido sus versos y que no se preocupe, que ha tomado buena nota de sus advertencias y que no tenga dudas, ya que sabe perfectamente el motivo que le ha llevado a aquellos lejanos desiertos:

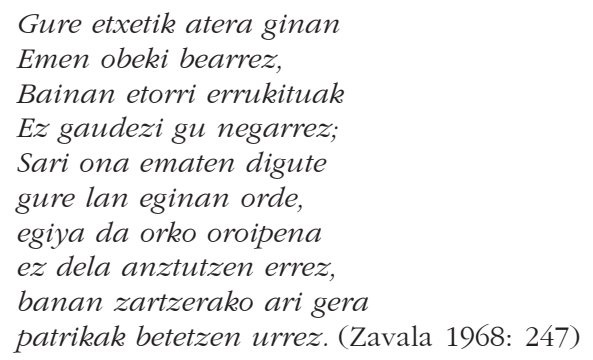

[Abandonamos nuestro hogar para mejorar, aunque vinimos apesadumbrados no estamos llorando. Nos han pagado un buen sueldo a cambio de nuestro trabajo, aunque es verdad que el recuerdo de la tierra no se olvida, pero estamos trabajando para nuestra vejez, para llenar los bolsillos de oro.]

\title{
5. HERRIMINA, EL DOLOR POR LA LEJANÍA DEL HOGAR
}

La esperanza en encontrar un futuro mejor o el deseo de alcanzar un mayor bienestar son los motores que dinamizan los movimientos migratorios (Serafín 2015: 272). Pero, para conseguir esos deseos las personas migrantes deben de abandonar la tie- 
rra que les vio nacer, con la consiguiente añoranza del hogar, la rabia por la imposibilidad de poder tener una vida mejor en la tierra que nos vio nacer o la melancolía que combina las memorias e ilusiones. Estas emociones se muestran reflejadas en los versos anónimos de título Agur. El vascófilo Francisco Egaña encontró estos bertsopaperak $^{14}$ en una librería madrileña y los publicó en la revista Bertsolaria. Posteriormente, José Manterola los incorporó a su obra Cancionero Popular. La versión que aparece en estas páginas está recogida de la recopilación Ameriketako Bertsoak de Antonio Zavala (1984: 23). En la composición se narra el viaje y la despedida de un emigrante hacia tierras americanas. El autor anuncia que parte hacia el nuevo continente con la esperanza de conquistar allí un futuro mejor que el que puede encontrar en su tierra, pero en su horizonte permanece inalterable la idea del retorno al origen.

\section{Triste daukat anima, \\ Biyotza miñduba, \\ Borondate argal au \\ Agitz nagituba: \\ Esperantza ez det izan \\ Beñere urrituba. \\ Erdia iñoz baño \\ Gaur aundiyagua!}

[Triste tengo el alma y dolorido el corazón, desconsolada mi débil voluntad. Nunca he perdido la esperanza que es hoy más fuerte que nunca.]

Amerikara nua,
Euskaldun gaztia,
Lutekiyan largarik
Nai dedan guztiya:
Zerubak agintzen dit
Gaur emen uztia,
Agin dezakeana
Bigar biurtzia.

[Soy un vasco joven que abandono mi tierra para ir a América. El cielo me ordena que marche hoy, pero también que regrese mañana.]

Testimonios como estos narrados por medio de los versos improvisados, y las emociones que en ellos se reflejan han sido, en ocasiones, los mecanismos de expresión de esas narrativas de la nostalgia y, al mismo tiempo, se constituían como una vía para exponer y dar a conocer estos lamentos de manera pública. Bien es verdad que la mayoría de estos versos tenían como objeto principal el cantar las penas del dolor de la emigración y de esa manera exorcizarlas. En este sentido, la improvisación de versos por parte de los emigrantes podía tener un efecto catártico y ayudarles a combatir y aligerar el peso de la nostalgia. No obstante, sin entrar a considerar las cualidades poéticas o literarias que pueden tener todas estas improvisaciones, considero que lo interesante es ver cómo comulgan la improvisación poética con las emociones de las personas emigrantes, o cómo utilizan estas personas de la improvisación como catalizador de las emociones que les ronda en su interior.

La nostalgia puede ser entendida como la subjetividad que motiva a los emigrantes a reordenar los símbolos o los anclajes necesarios para reproducir, replicar o

\footnotetext{
${ }^{14}$ Improvisaciones escritas en papel.
} 
reinventar sus nuevas identidades y culturas en los lugares de destino (Hirai 2009: 16). La nostalgia, al igual que la memoria funciona como mecanismo para reconstruir el presente y proyectar el futuro, en base a referencias pasadas. La nostalgia ayuda a la reinterpretación y fijación del pasado y facilita la recreación de la identidad. De alguna manera, ofrece legitimidad a hechos y a las vivencias del pasado. En la nostalgia aparecen experiencias que han quedado incorporadas como parte vital de la existencia y que constituyen lugares y objetos de memoria. Esta idea de la nostalgia como recreación de la memoria puede remitir a la idea de habitus de Bourdieu en la medida que es una historia encarnada, interiorizada que se aprende mediante el cuerpo (Prat 2008: 159).

Manex Etchamendy, emigrante vasco que partió a finales del siglo XIX para trabajar como pastor en tierras de California, cantó estos versos el día de Año Nuevo de 1895. En ellos evoca sus recuerdos de infancia y trae a la memoria a sus padres, a los que añora en determinadas fechas, para mostrarles su amor y convertirlos en engarces idealizados que le unen con el pasado:

\author{
Aita'amez gare orroitzen \\ Eta begiak bustitzen \\ Urrun gaigira kausitzen. \\ Gur'haurrean hek bazakiten \\ Bai gure ongi altxatzen, \\ Etsenplu onen emaiten; \\ Gutaz ziren urrikaltzen. \\ Eskerrak ditut bihurtzen. (Lafitte 1972: 32)
}

[Los ojos se humedecen al recordar a nuestros padres en la lejanía. En nuestra niñez sabían protegernos bien, nos ofrecían un buen modelo y se compadecían de nosotros. Ahora les ofrezco mi agradecimiento.]

La nostalgia recogida en esta composición se apoya en el poder evocador de situaciones, acciones, conmemoraciones o referentes personales que actúan como una parte importante de la articulación del pasado, presente y futuro. Manex Etchamendy también es el creador de la composición Sor lekuaren amodioa ${ }^{15}$. En estos versos el autor da cuenta de las emociones íntimamente relacionados con la herrimina, la nostalgia. Herrimina viene a representar el dolor por la tierra abandonada, por la ausencia de los prados verdes del País Vasco, por la lejanía del paisaje suavemente montañoso o por el recuerdo de la compañía idealizada del sirimiri (la lluvia fina).

\author{
Gure sor leku maiteez \\ zonbat ez gare orroitzen! \\ Arrangurarikan baizen \\ ez dut nik bemen aditzen. \\ Egundainotik bakotxa \\ bere minak du eritzen. \\ Ni ere neure kasuaz \\ orai hasten naiz mintzatzen
}

[Cuanto recordamos nuestra tierra, no escucho más que lamentos, cada cual se enferma con su pena. Ahora empezare yo a contar las mías.]

\footnotetext{
${ }^{15} \mathrm{El}$ amor hacia el lugar de origen.
} 


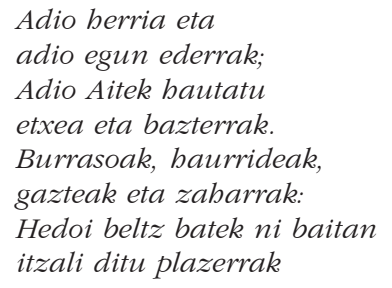

[Adiós a mi tierra, a los buenos momentos, adiós a mi casa y a los rincones adoptados por mis padres, adiós padres, familia, jóvenes y ancianos. Una nube negra ha ensombrecido mis alegrías.]

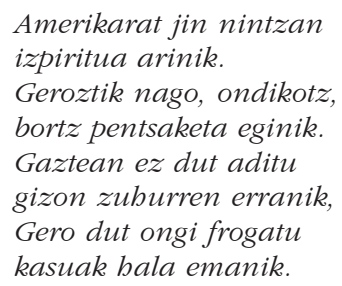

[Marché hacia América con espíritu ligero, desde entonces muchas veces he reflexionado sobre ello. Después de conocer esta vida creo que no eran palabras sensatas aquellos cantos de sirena que escuché de joven y que animaban a partir.]

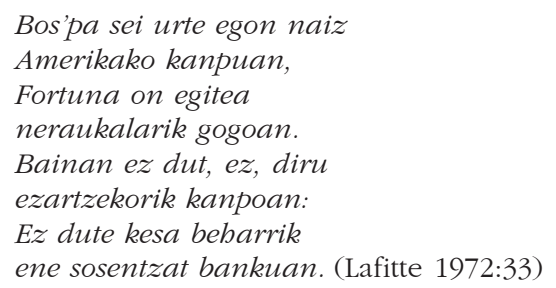

[Llevo cinco o seis años en tierras de América, llegué aquí con la intención de conseguir una buena fortuna. Pero no ha sido así, no tengo dinero, y serán pocas las preocupaciones que tendrán los banqueros con mis ahorros.]

El improvisador anteriormente presentado como Nevadako artzaina (El pastor de Nevada) da cuenta de las insatisfacciones, de los disgustos y el descontento que sufrían los pastores vascos en Estados Unidos por su sufrida y solitaria vida. En la composición vuelve a aparecer la nostalgia, la añoranza por el pasado y el anhelo que le produce el recuerdo de un estilo de vida y de una manera de ser que le transportan a su lugar de origen (Hirai 2009: 124).

Hemeretzi ehun-ta berrogoi-ta zortzian,

Sor lekhu utzi dut adin ederrian.

Orai hemen naiz bizi Nevada-mendian

Gogoa ilhun eta penak bihotzian,

Desertuetan artzain bakhartasunian.

[En 1948, estando en plena forma he abandonado mi tierra. Ahora vivo y trabajo de pastor en los montes de Nevada, con el semblante triste y el corazón apenado en la soledad del desierto.] 
Bakhartasuna eta sor lekhutik urrun;
Pena haundiagorik ba othe da nibun?
Nehor ikusi gabe zazpi zortzi egun.
Etcherik ere bichtan ezpeita ezagun.
Gau egun oroz nago arthaldea lagun.

[¿Existe algo más doloroso que encontrase solo y lejos del hogar, sin ver a nadie en una semana, sin divisar ninguna casa? Todos los días y noches así, con la única compañía del rebaño.]

Goraintzi urrunetik herritarrendako, Horgo orhoitzapenak ez tut ahantziko. Zombait urthegno ditut hemen phasatuko.

Hitzemaiten dauziet huntaz segur nago:

Ni segurik ez naiz ez hemen zahartuko. (Jauregi 1950: 13)

[Quiero saludar a mis vecinos desde la lejanía, no os olvidaré. Aunque debo de vivir aquí algunos años, os declaro que estoy seguro que aquí no envejeceré.]

El regreso a la tierra de origen es un pensamiento que acompaña siempre a las personas que han debido emigrar, aunque como apuntan Douglass y Bilbao (citados en Orduña 2012: 427) en las ocasiones en que estos pastores regresaban a sus terruños natales veían como aquellas imágenes y recuerdos que habían mantenido custodiados de manera inalterable en sus entrañas cambiaban y acababan modificándose, lo que les hacía sufrir otras formas de destierro también en su país de origen.

Avionak pasatzian, ene doloria!

Batean hegaldatuz nik nuke Loria

Gogotik utz nezake hau mundo berria

Zure ganat jiteko en'Euskal Herria. (Mehats 2005: 129)

[Qué dolor, cuando veo volar un avión, quisiera tener el gozo de volar, con gusto abandonaría este nuevo mundo para acudir hacia ti, Euskal Herria.]

Las tierras de acogida en donde estos pastores trabajaban se encontraban muy lejos de los hogares desde los que ellos habían partido. La distancia kilométrica que debían de recorrer para llegar hasta sus hogares era inmensa, a lo que se añadía el obstáculo insalvable de la presencia del océano Atlántico separando ambos continentes, que no permitía ni el sueño de recorrer el camino de vuelta.

Hunarat jin orduko zabaldu begia

Falta dut sor etchea neure jauregia

Ezpalitz gibelerat hoin luze bidia

Aspaldian nindaiken harat hurbildia. (Mehats 2005: 139)

[Se me han abierto los ojos al llegar aquí, echo en falta mi casa natal, mi "palacio", si no fuera porque tengo detrás un larguísimo camino ya hubiese regresado.]

\section{LA IMPROVISACIÓN PARA COMBATIR LA DUREZA DEL TRABAJO}

Las condiciones del pastoreo trashumante eran muy duras. Los pastores pasaban semanas solos en las montañas y desiertos del Oeste americano con la única compa- 
ñía de un caballo y un par de perros que les ayudaban en el cuidado del rebaño. En los páramos, el pastor se sentía solo, abandonado y perdido en un mundo extraño que no era el suyo. En contraste con los paisajes y recuerdos de su tierra natal en los que revivía unos recuerdos de felicidad y de alegría, los parajes del Oeste Americano se mostraban como un inmenso espacio de soledad, de abandono, de rutina, en la que todos los días de la semana se mostraban iguales, donde no había ninguna diferencia entre los días de trabajo y los de los días de fiesta.

\author{
Igande astelegun guziak berdinak \\ Bizar handi batekin arropa zikinak \\ Zer amerikanoak ginen euskaldunak \\ Dolar batzuen gatik erdi salbai inak. (Mehats 2005: 140)
}

[Todos los días son iguales, no hay lunes ni domingo. Y aquí estamos con una larga barba y ropa sucia, ¿qué clase de americanos somos los vascos que a cambio de unos pocos dolores nos convertimos en unos salvajes?]

A propósito de la soledad en la que vivían estos pastores, Orduña (2012: 416) trae a colación la campaña publicitaria de la compañía de telecomunicaciones AT\&T que fue protagonizada por el pastor navarro Dionisio Txoperena. La campaña publicitaria giraba en torno a la soledad que padecían en su trabajo pastores como Dionisio y las posibilidades de cobertura que esta empresa de telefonía ofrecía para romper su aislamiento. Esta campaña de publicidad tuvo mucho éxito y seguimiento entre los vascos de ambos lados del Atlántico.

No sólo la soledad imponía su crueldad a estos pastores, también el desconocimiento del idioma inglés impedía la comunicación con las pocas personas que cada diez o quince días acudían hacia ellos para llevarles las provisiones. La incomprensión lingüística hacía que aumentase la inquietud y el sentido de la desesperación (Serafín 2015: 273). La incomunicación fruto del desconocimiento del idioma inglés aparece en esta estrofa cantada por Martin Goikoetxea originario de Gorriti (Navarra) en la que narra las primeras impresiones al llegar a tierras americanas:

\author{
Honera etorrita hasera zorrotza \\ Hizketan ere ez jakin \\ Hau leku arrotza \\ Leku andiak eta \\ Ibilera motza \\ Amerikan bizi ta \\ Euskadin biotza \\ Jaiotako lekuan nahi det heriotza. (Mallea-Olaetxe 2003: 369)
}

[Son complicados los comienzos en este lugar, ni siquiera sabíamos hablar, extraño lugar. Espacios inmensos para dar pequeños pasos. Vivo en América, pero mi corazón está en Euskadi, por eso quiero morir donde he nacido.]

Además de tener que hacer frente a la soledad, de soportar el rigor del clima del desierto y de la dificultad de comunicarse en inglés, los pastores vascos también debían de combatir a los numerosos animales salvajes que acechaban los rebaños. La presencia de estos animales salvajes exigía la atención del pastor de manera constante, no solo para preservar al ganado de cualquier ataque, sino para protegerse de estos 
posibles ataques. En esta composición creada en 1949 el autor describe las peripecias de un pastor para hacer frente a un grupo de osos que se acercaron al rebaño con la intención de atacar a sus ovejas:

\author{
Hiru hartz sartu dira \\ beste artaldera, \\ Han eginen zutela \\ gustuko fera. \\ Kaiet'ek, ttutta-beltxa \\ barturik eskura, \\ Hartz-ama botatu du \\ lau zangoez gora. (Lafitte 1972: 231)
}

[(En otra de las estrofas cuenta cómo un oso atacó a una parte del rebaño). Tres osos han penetrado en el rebaño, pensando en hacer buen negocio, Kaiet cogió el tubo negro y disparó a la madre que quedó patas arriba.]

Al igual que en el anterior verso, el siguiente describe la presencia de animales salvajes en los lugares por donde acudían los pastores para dar de comer a sus rebaños. En la composición de donde ha sido extraída esta estrofa, Josetxo Yanzi, pastor originario de Lesaka (Navarra) da cuenta de la vida de los pastores en los montes del Oeste americano, y el peligro que representa el vivir constantemente rodeados de animales salvajes, de alimañas peligrosas que atacan al ganado o al pastor, si no permanece vigilante:

\author{
Bakardadeko basamortuan \\ Nola baigera bizitzen, \\ Koiote, kato, legoi ta suge \\ Bertzerik ez da aurkitzen; \\ Sarritan gaude kanpo barruan \\ Oien orruak aditzen \\ Salvaje-modura bizi gera \\ Ezerk ez gaitu izitzen \\ Esan laiteke geuren bizia \\ Ez dugula estimatzen. (Zavala 1968: 253)
}

[Como vivimos en la soledad del desierto, nos topamos con coyotes, gatos salvajes, pumas y culebras. A menudo, cuando estamos en la tienda de campaña escuchamos sus alaridos. Vivimos de manera salvaje, ya no nos asusta nada, se podría decir que ni siquiera estimamos nuestra propia vida.]

Han sido numerosas las referencias en versos improvisados a la presencia de animales amenazantes en la cotidianeidad del pastoreo. En esta composición de título Nevadako berriak — Noticias de Nevada- el pastor, León Bereau, describe con humor los peligros a los que deben enfrentarse los pastores. Ente los más significativos están la continuada presencia de animales salvajes en los lugares en los que deben desarrollar su trabajo:

\author{
Basa piztiak inguratuak \\ Emen ditugu onduan \\ Basa-zaldi ta leoi, koiote, \\ Domadorien moduan;
}




\author{
Animaliak oien izenak \\ Beti aitzia banuan \\ Amakina bat ikusteko' ere \\ Baudaukagu munduan! (Zavala 1968: 292)
}

[Parecemos domadores, ya que estamos rodeados de los animales salvajes: caballos, pumas y coyotes. Anteriormente había oído hablar de ellos, en este mundo hay que conocer de todo.]

Además, las condiciones de habitabilidad en los refugios de pernocta del pastor no se caracterizaban por la confortabilidad. Durante los meses de primavera y verano, aproximadamente desde abril a septiembre los pastores debían dormir en simples tiendas de lona, fáciles de recoger y llevaban su enseres en mulas o caballos de carga (Orduña 2012: 420), así se facilitaba la movilidad del rebaño en la búsqueda de buenos pastos. Durante los duros meses invernales, el ganadero propietario facilitaba un carro-campo que permanecía asentado en un lugar y que servía de refugio para protegerse de las inclemencias del tiempo, del frio, la nieves y las heladas:

\author{
Zenbat urrats eman nik Ameriketan \\ Zer toki tristiak diren nago pentsaketan \\ Beti ardiekilan mendi penosotan \\ Batere karparik gabe denbora xarretan. (Mallea-Olaetxe 2003: 57)
}

[Cuántos pasos he dado yo en América, pienso que son lugares tristes, siempre con las ovejas en aquellos desdichados parajes, sin un techo donde poder cobijarse los días de mal tiempo.]

En la soledad de las montañas y del desierto árido del Oeste, el perro y el caballo eran sus únicos compañeros. En muchos versos estos animales son recordados con afecto, como reflejan estos versos de Jesús Goñi que el único rastro de humanidad que encontraba en su trabajo era la mirada de sus perros. Éstos miraban con cariño al pastor y en esa mirada podían reflejarse lazos de solidaridad y complicidad por la dureza de la vida de ambos:

\author{
Artzain jarri nintzan mendian \\ Neguko sasoin betian \\ Ardi anitz aitzinean eta \\ Bi xakurren konpanian \\ Arkiekilan ibilki nintzan \\ gau eta egun guzian \\ bi xakurrak eni begira \\ irudiz min biotzian. (Mallea-Olaetxe 2003: 353)
}

[Comencé a trabajar de pastor en pleno invierno, rodeado de ovejas con la compañía de dos perros. El trabajo con las ovejas se alargaba día y noche, los dos perros me observaban con el corazón afligido.]

\title{
7. ALGUNAS IDEAS PARA EL ANÁLISIS
}

Como he ido señalando en páginas anteriores, los versos improvisados se constituyen como un medio comunicativo de primer orden que utilizado por los pastores vascos 
emigrantes para expresar las emociones producidas por la lejanía de sus hogares y por las duras condiciones en las que debían desarrollar su trabajo. Por ello se puede pensar que el análisis de la producción de versos improvisados contribuye al conocimiento de la memoria de esta emigración, ya que en torno a estos versos se encuentra una visión poliédrica y multivivencial del hecho migratorio. Alejado de su lugar de origen y de su anterior cotidianeidad el pastor vasco emigrante desarrolló un mundo simbólico que le permitía mantener vivos aspectos importantes de su identidad y eso se canalizaba a través de composiciones orales rimadas. Hay que tener en cuenta que a finales del siglo XIX y principios del siglo XX, cuando la emigración de pastores a América alcanzó sus momentos más significativos, una gran parte del pensamiento de los vascos estaba

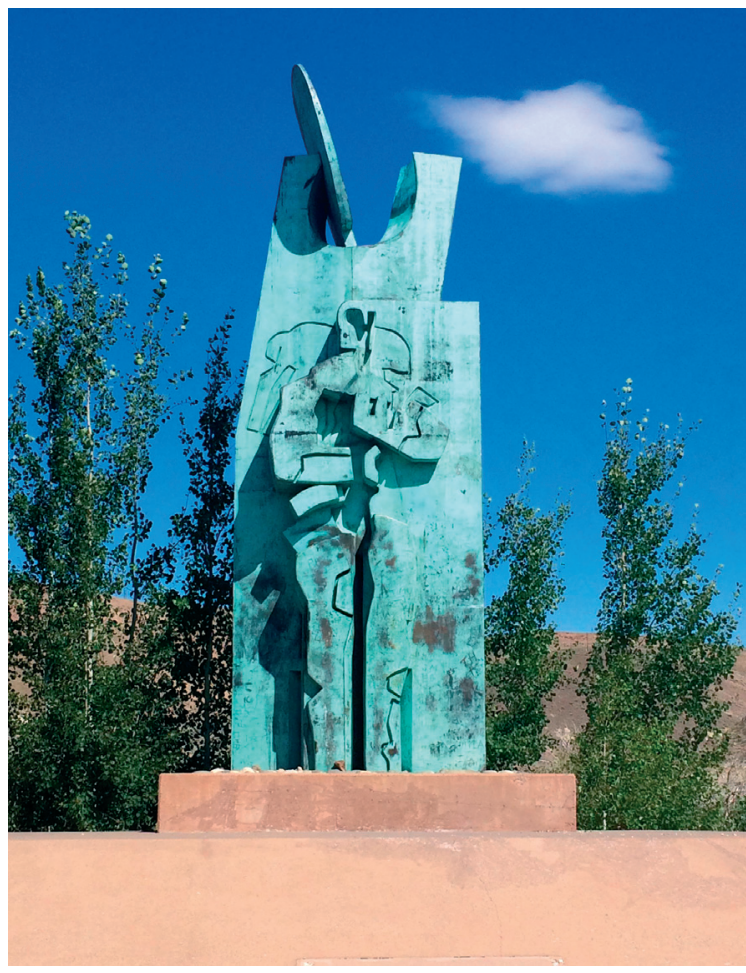

IMAGEN 4.- Monumento en homenaje al pastor vasco en Reno (Néstor Basterretxea 1989). Fotografía del autor. vehiculizada por la importancia que la oralidad tenía en esta sociedad (Zulaika 2003).

Un universo simbólico en el que la nostalgia ocupaba un lugar privilegiado, ya que "no solo es una emoción que evoca el lugar de origen, sino que contribuye a la construcción de un conjunto de actitudes relacionadas con el terruño y practicas socioculturales de movilidad" (Hirai 2014: 92). El profesor de la Universidad de California en Los Ángeles, Eduardo Mayone (1982) al estudiar la diáspora portuguesa en USA, da cuenta de unas producciones poéticas similares realizadas por la emigración portuguesa a la que denomina "poesía vivencial", en las que se reflejan las emociones asociadas a la nostalgia. En el caso que nos ocupa, los versos realizados por los pastores vascos emigrantes, también podrían calificarse como poesía vivencial, ya que tienen una clara función testimonial evocadora o emotiva que es perceptible de manera directa. Es decir, se erigen en textos evocadores complejos y multifacéticos que construyen la representación del proyecto migratorio.

Hoy en día sería unánime el acuerdo en considerar la literatura o el cine como productos culturales con una enorme relevancia social y que las representaciones que en esos productos culturales se reflejan son elaboraciones de unos discursos sociales e históricos. De la misma manera, estos versos vinculados con la emigración al norte de América se constituyen como discursos sociales e históricos o como atalayas desde donde poder observar cómo se va construyendo la realidad social de esta emigra- 
ción vasca. En este sentido, la improvisación de versos ha servido como catalizador, constructor y transmisor de información y emoción en el proyecto migratorio. En nuestra opinión esta cadena de transmisión de memorias ha recogido con atino la emoción

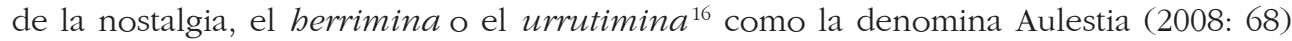
y estas emociones han quedado incorporados como parte de la identidad del grupo emigrante.

Se habían realizado estudios que analizaban las relaciones entre la emigración y la improvisación poética vasca, por citar los más interesantes tenemos: Antonio Zavala 1984, Joxe Mallea-Olaetxe 2003, Gorka Aulestia 2008, Joserra Garzia 2008, Asun Garikano 2009 y la tesis doctoral de Claude Mehats (2004) ${ }^{17}$. Pero en estos análisis no se ha tomado en consideración la importancia que la emoción del creador de las poesías improvisadas tiene para la explicación del fenómeno. El mundo de la emoción está estrechamente implicado con la narración de la emigración a tierras americanas.

Como bien dice la profesora Jone Miren Hernández el bertsolarismo es un molde expresivo de la cultura, que produce vivencias por medio de la experiencia emocional (2011: 7). Por lo tanto no podemos reducir el bertsolarismo a un instrumento comunicativo, que contaba lo que aparecía ante los ojos de la comunidad vasca. Como diría Goffman (2006: 11) estos elementos (emigración, bertsoa y emoción) se encuadran e interactúan en un marco interpretativo que es compartido, adquieren sentido y se convierten en significativos.

\section{BIBLIOGRAFIA CITADA}

Álvarez Gila, Oscar. 1998. "Urruñako 1853ko Euskal Jaiak, Ameriketako euskal emigrazioa eta eliza”, en Eusko Ikaskuntza (ed.), Antoine d'Abbadie 1897-1997: Congrés International-Ezhoiko kongresua. Donostia: Eusko Ikaskuntza y Euskaltzaindia.

Álvarez Gila, Oscar. 2004. "Emigraciones de Europa a América en los siglos XIX y XX: El caso de la emigración vasca". Cuadernos CANELA. Actas de la confederación académica nipona, española y latinoamericana XVI: 73-105.

Álvarez Gila, Oscar y José María Tapiz Fernández. 1996. «Prensa nacionalista vasca y emigración a América (1900-1936)". Anuario de estudios americanos 53(1): 232-260.

Aristorena, Pablo J. 1992. Nafarroako bertsolaritza. Pamplona: Gobierno de Navarra.

Arrizabalaga, Marie P. 2010. "Cent ans d'émigration basque française en Amérique du Nord: Synthèse et nouvelles perspectives (1860-1960)", en Adrián Blázquez (ed.), Emigration de masse et émigration d'élite cers les Amériques au XIXe siècle. Le cas des Pyrénées basco-béarnaises: 113152. Orthez: Editions Gascogne.

Aulestia, Gotzon. 2008. "Euskal literatura Ameriketan". Sancho el Sabio: Revista de cultura e investigación vasca 29: 65-85.

Azcona, José Manuel. 1998. "Cultura vasca contemporánea en los países del Cono Sur”, en William Douglass (ed.), The basque Diaspora: 25-43. Reno: University of Nevada Press.

\footnotetext{
${ }^{16} \mathrm{Si}$ bien "herrimina" se entiende como el dolor que produce la añoranza de los lugares de origen, "urrutimina" corresponde al dolor que produce la lejanía.

${ }^{17}$ Esta tesis con el título: Les Basques de France aux Amériques: XIXème-XXème siècles: recherche sur des aspects spécifiques d'une émigration organisée fue dirigida por el Profesor Marc Agostino y defendida en la Universidad de Burdeos-Montaigne. Posteriormente fue publicada en el 2005, bajo el titulo de organisation et aspects de l'emigration des Basques de France en Amérique: 1832-1976.
} 
Bieter, Jhon y Mark Bieter. 2005. Un legado que perdura, la bistoria de los vascos en Idabo. VitoriaGasteiz: Gobierno Vasco.

Bilbao, Iban y Chantal Eguiluz. 1984. Vascos llegados al puerto de Nueva York 1897-1902. VitoriaGasteiz: Diputación Foral de Álava.

Davant, Jean-Louis. 1977. "Lore jokoen ingurumenaz". Soziolinguistika Aldizkaria 25: 65-75.

Dávila, Paulí. 1995. Lengua, escuela y cultura. Bilbao: Universidad del País Vasco/Euskal Herriko Unibertsitatea.

Douglass, William A. y Jon Bilbao. 1986. Amerikanuak, Vascos en el Nuevo Mundo. Bilbao: Universidad del País Vasco /Euskal Herriko Unibertsitatea.

Eizagirre, Ana. 2007. Abozko bitzetatik idatzietara: ikasi eta jardun. Vitoria-Gasteiz: Gobierno Vasco. Etxamendy, Pedro Juan. 2004. California’ko bertsolari eta musikari. Tolosa: Auspoa.

Jauregi, Koldo. 1950. "Nevadatik". Egan 2: 13-15.

Fernández de Larrinoa, Kepa. 1992. Estatu Batuetako mendebalde urrutiko Euskal Jaiak. VitoriaGasteiz: Gobierno Vasco.

Fernández Vicente, María José. 2014. "De la tragedia de Saida al drama del Heliopolis. El problema migratorio en España (1881-1907)", en Almudena Delgado Larios (coord.), Conflictos y cicatrices: fronteras y migraciones en el mundo bispánico: 247-271. Madrid: Dykinson.

Gachiteguy, Adrien. 1955. Les basques dans l'ouest americain. Belloc: Editions Ezkila.

Garikano, Asun. 2009. Far Westeko Euskal Herria. Pamplona: Pamiela.

Garzia, Joserra. 2008. "Baina bihotzak dio... (Emigrazioa bertsotan)”. Bertsolari 70: 24-41.

Garzia, Joserra, Andoni Egana y Jon Sarasu. 2001. Bat-bateko bertsolaritza: gakoak eta azterbideak. San Sebastian: Bertsozale Elkartea.

Goffman, Erving. 2006. Frame analysis: los marcos de la experiencia. Madrid: Centro de Investigaciones Sociológicas.

Hirai, Shinji. 2009. Economía política de la nostalgia. Un estudio de la transformación del paisaje urbano en la migración transnacional entre México y Estados Unidos. México: Universidad Autónoma Metropolitana.

Hirai, Shinji. 2014. "La nostalgia, las emociones y significados de la emigración transnacional" Nueva Antropología 18: 77-94.

Hernandez, Jone Miren. 2011. "Bertsolarismo: Palabras que emocionan, emociones hechas palabra". en Mari Luz Esteban, Juan Antonio Flores y Julián López (eds.) In-corporaciones antropológicas: Análisis desde el cuerpo y las emociones: 1219-1228. León: Asociación de Antropología de Castilla y León "Michael Kenny" y FAAEE.

Lafitte, Piarres. 1972. Manex Etchamendy bertsularia (1873-1960). Tolosa: Auspoa

Lhande, Pierre. 1971. La emigración vasca. San Sebastián: Aunamendi.

Mallea-Olaetxe, Joxe. 2003. Shooting from the Lip: Bertsolariak Ipar Amerikan, Improvised BasqueVerse Singing, Reno: North American Basque Organization.

Mallea-Olaetxe, Joxe. 2005. "Basque Rap in American west: Bertsolariak", en Joseba Zulaika y Samuel G Armistead (eds.), Voicing the momento: 215-227. Reno: North American Basque Organization

Mallea-Olaetxe, Joxe. 2009. The Basques of Reno and the Northeastern Sierra. San Francisco: Arcadia.

Mayone Dias, Eduardo. 1982. Cantares de Alem-mar. Una colectanea de poesía vivencial popular de emigrantes portugueses en Estados Unidos. Coimbra: Universidad de Coimbra.

Medina, Xabier. 1997. Los otros vascos. Las migraciones vascas en el siglo XX. Madrid: Fundamentos.

Mehats, Claude. 2005. Organisation et aspects de l'emigration des Basques de France en Amérique: 1832-1976. Vitoria-Gasteiz: Servicio de Publicaciones del Gobierno Vasco.

Mehats, Claude (ed). 2005. Ibolditik Arizonera 1952-1959, les chants basques de Charles Ugalde. Bayonne: Maiatz.

Oiarzabal, Pedro J. 2009. Gardeners of identity. Basques in the San Francisco Bay Area. Reno: Center of Basque Studies.

Olaziregi, Maria Jose. 2012 "Worlds of Fiction: An introduction to Basque Narrative", en Maria Jose Olaziregi (ed.), Basque Literary History: 137-200. Reno: Center of Basque Studies.

Orduña Portús, Pablo. 2012. "End of the trail. Los últimos pastores roncaleses en las montañas de Nevada (USA)». Revista de Dialectología y Tradiciones Populares 67: 409-430.

Otaño, Pedro María. 1994. Beste bertsoak. Tolosa: Auspoa. 
Perez Aldasoro, Pio. 2014. Joxe Zapirainen bertso-malkoak edo nola arindu sufrimendua bertsoaren bidez. Amorebieta: Ayuntamiento de Amorebietako e Instituto Labayru.

Pildain, María Pilar. 1984. Ir a América, la emigración vasca a América (Guipúzcoa 1840-1870). San Sebastián: Sociedad Guipuzcoana de Ediciones y Publicaciones.

Pipkin, George C. 1997. Pete Aguereberry, urbea Kalifornian. Heleta: Jean Curutchet Argitaletxea.

Prat, Joan. 2008. "Antropología de la memoria en la obra de Teresa del Valle". Ankulegi 12: 15-165.

Saitua, Iker. 2015. «Enforced socialism? La ley Taylor de pastoreo y la redistribución de la tierra en el estado de Nevada (1934-1945)", en Pilar Folguera, Juan Carlos Pereira et al. (eds.), Pensar con la historia del siglo XXI: 2119-2136. Madrid: UAM ediciones. Disponible en: <http://www.uam.es/ss/ Satellite/es/1242675314514/1242687568365/UAM_Libro_FA/libro/PENSAR_CON_LA_HISTORIA DESDE_EL_SIGLO_XXI.htm>. Fecha de acceso: 20 oct. 2015.

Santiso González, María Carmen. 1998. Los vascos y América. Cien años de torrente migratorio hacia América. Diáspora vasca y enganchadores (18830-1930). Bilbao: Fundación BBV.

Serafín, Silvana. 2015. "Algunas reflexiones sobre la novela de la emigración italiana en Argentina" Estudios Italianos Vol. III(1): 271-278.

Sorozabal Esnaola, Koldo. 1992. Pastores euskaldunes en América. Vitoria-Gasteiz: Gobierno Vasco.

Urkizu, Patricio (ed). 1977. Anton Abbadiaren koplarien guduak: Bertso eta aire zenbaiten bilduma 1851-1897. San Sebastián: Eusko Ikaskuntza y Euskaltzaindia.

Valcárcel, Amelia. 2010. La memoria y el perdón. Barcelona: Herder.

Xarriton, Piarres. 1992. Jose Mendiague (1845-1937) Haren bizia eta haren kantuak. San Sebastian:. Etor.

Zavala, Antonio. 1968. Paulo Yanzi ta beren lagunen bertsoak. Tolosa: Auspoa.

Zavala, Antonio. 1983. Kubako gerra. Tolosa: Auspoa.

Zavala, Antonio. 1984. Ameriketako bertsoak. Tolosa: Auspoa.

Zulaika, Joseba. 2003. Bertsolaritzaz bi saio. San Sebastian: Bertsozale Elkartea.

Fecha de recepción: 29 de febrero de 2016.

Fecha de aprobación: 5 de julio de 2016. 